\title{
Engineering PdAu Nanowires for Highly Efficient Direct Methane Conversion to Methanol Under Mild Conditions
}

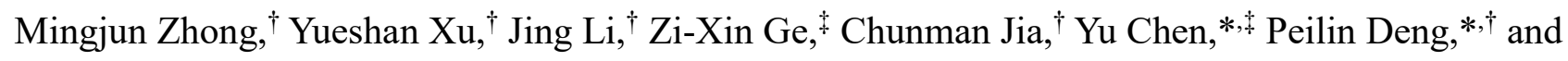
Xinlong Tian ${ }^{* \dagger}$

\footnotetext{
$\dagger$ State Key Laboratory of Marine Resource Utilization in South China Sea, Hainan Provincial Key Lab of Fine Chemistry, School of Chemical Engineering and Technology, Hainan University, Haikou 570228, China

$\$$ School of Materials Science and Engineering, Shaanxi Normal University, Xi'an 710062, China
}

Corresponding authors: Yu Chen (ndchenyu@gmail.com); Peilin Deng (dengpeilin@hainanu.edu.cn);

Xinlong Tian(tianxl@hainanu.edu.cn) 


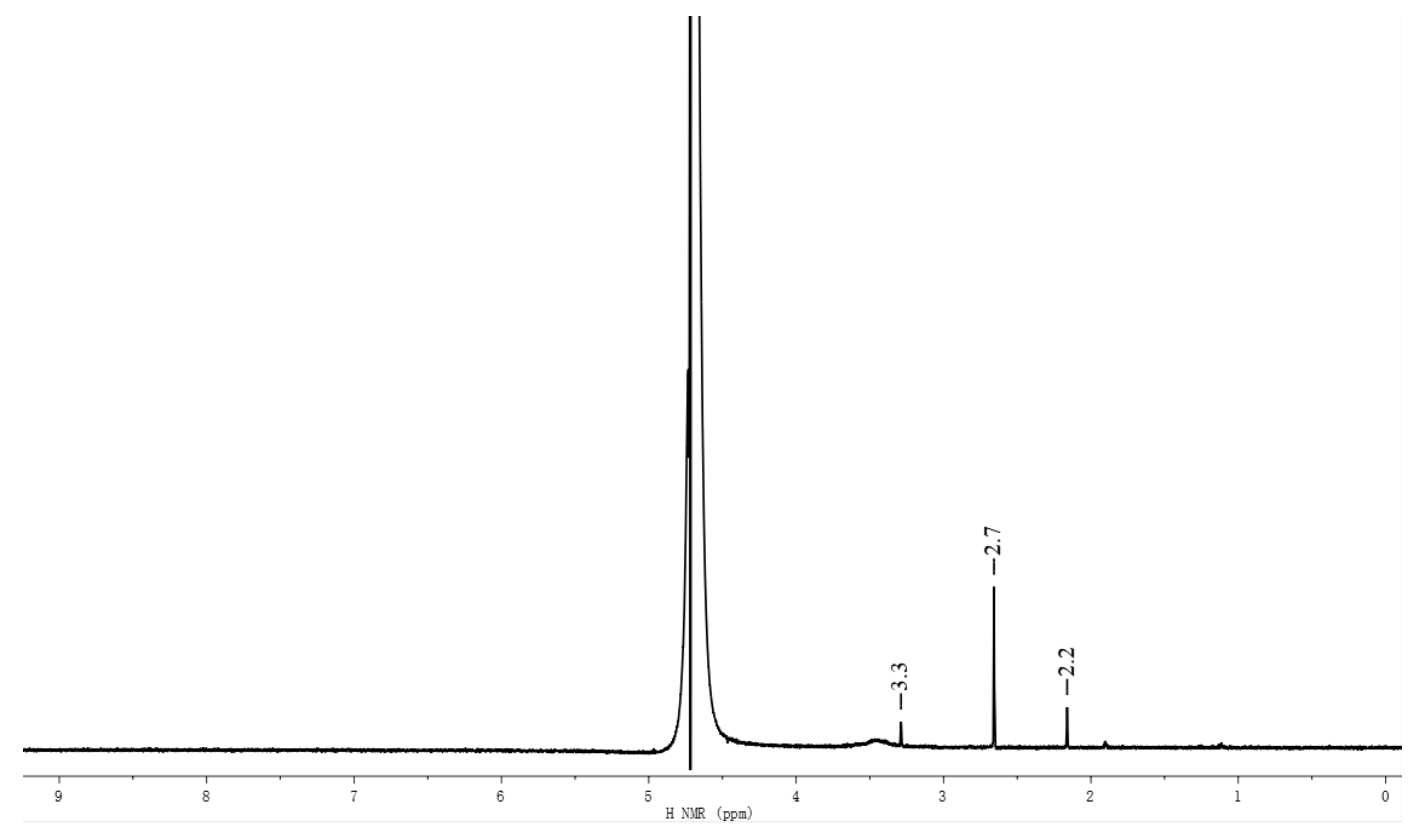

Figure S1. ${ }^{1} \mathrm{H}$ NMR result of liquid product for the alloyed $\mathrm{Pd}_{12} \mathrm{Au}_{1} \mathrm{NWs}$. 


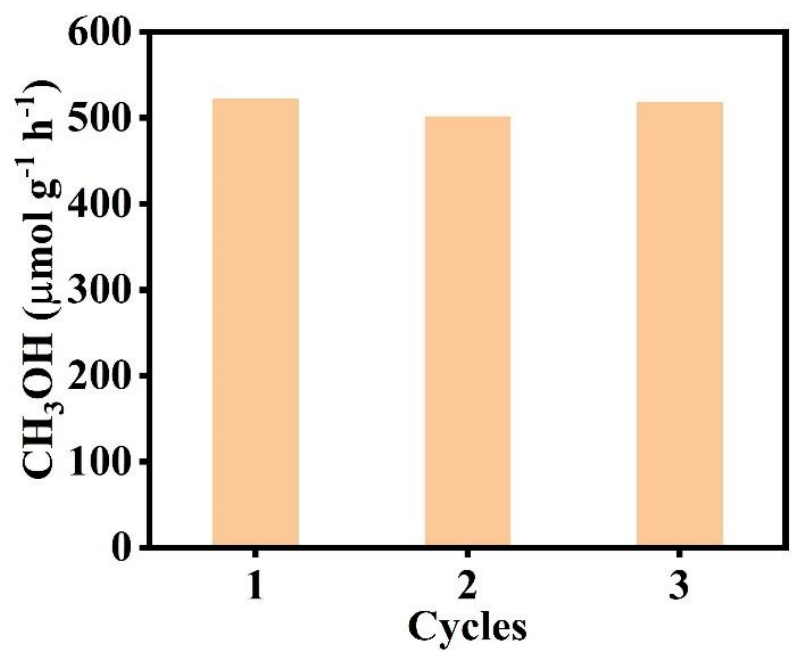

Figure S2. Catalytic Stability test over the alloyed $\mathrm{Pd}_{12} \mathrm{Au}_{1}$ NWs. The Reaction conditions: $\mathrm{P}\left(\mathrm{CH}_{4}\right)=3.0$ $\mathrm{MPa}, \mathrm{P}\left(\mathrm{O}_{2}\right)=0.5 \mathrm{MPa}, \mathrm{n}\left(\mathrm{H}_{2} \mathrm{O}_{2}\right)=500 \mu \mathrm{mol}, \mathrm{T}=70^{\circ} \mathrm{C}$. 